\title{
Decline in function and life expectancy of older persons with cerebral palsy
}

\author{
David Strauss $^{\mathrm{a}, *}$, Kelly Ojdana ${ }^{\mathrm{a}}$, Robert Shavelle ${ }^{\mathrm{a}}$ and Lewis Rosenbloom ${ }^{\mathrm{b}}$ \\ ${ }^{a}$ University of California Life Expectancy Project, 1439 - 17th Avenue, San Francisco, CA 94122-3402, USA \\ ${ }^{\mathrm{b}}$ Royal Liverpool Children's NHS Trust, Eaton Road, Liverpool L12 2AP, UK
}

\begin{abstract}
The authors studied the pattern of functional abilities and decline of skills in adults with cerebral palsy. The data source was the California Developmental Disabilities data base, which included 904 subjects of age 60. For those individuals who are mobile when they become adults, there is a marked decline in ambulation, especially in late adulthood, and few of the 60 year-olds who walked well preserved this skill over the following 15 years. Older subjects frequently also lost the ability to dress themselves. Many other skills, however, seemed to be well preserved, including speech, self-feeding and the ability to order meals in public. Whereas the great majority of young adults lived in their families' home or in small private group homes, $18 \%$ of the 60 year-olds lived independently or semi-independently, and $41 \%$ resided in facilities providing a higher level of medical care. Survival rates of the ambulatory older adults were only moderately worse than the general population. Survival was, however, much poorer among those who had lost mobility.
\end{abstract}

Keywords: Cerebral palsy, adults, activities of daily living, mortality, survival, decline in function

\section{Introduction}

Much of the emphasis in cerebral palsy (CP) is on the pediatric aspects. Quite properly, great attention is paid to therapies to maximize the child's potential for speech, ambulation and other functions. There is a large literature on medical conditions of children with cerebral palsy. Researchers have studied the developmental trajectory of children with $\mathrm{CP}$, considering questions such as the child's chance of learning to walk [30]. There is also a considerable literature from around the world on survival of children and young adults with CP $[7,12,16,20-22,38,40]$.

By comparison, there has been less attention paid to adults and elderly persons with CP. The subject is important because such persons are subject to various medical conditions that are uncommon in children $[6$, $18,28]$, and because they are apt to lose some of the

* Address for correspondence: David Strauss, Ph.D., F.A.S.A., University of California Life Expectancy Project, 1439 17th Avenue, San Francisco, CA 94122-3402, USA. Tel.: +1 415731 0250; Fax: +1 415731 0290; E-mail: Strauss@LifeExpectancy.com. functional abilities acquired in childhood [3,8,18,27$29,43]$. We have noticed that personal web sites created by those with cerebral palsy lament the lack of information available on what can be expected as they age. The research that has been published on such questions has been limited to small studies, as most of the cerebral palsy data bases do not have follow-up past early adulthood [7,12,16,20-22].

Both the literature and clinical experience indicate a high prevalence of medical problems in adults with CP. Joint stiffness and muscle contractures are common, as is degenerative osteo-arthritis. Neurological degeneration is also seen, especially in the cervical spine [26-29, 43]. Many subjects experienced considerable cervical pain: one study reported this in nearly $50 \%$ overall and $75 \%$ among subjects with dyskinesia [28]. Epilepsy is common in adults, $23 \%$ of whom have had a seizure in the last 12 months [37]. Urinary tract infections and incontinence are also common, especially in the nonambulatory, as are hearing and vision problems [28]. Less commonly, spinal cord degeneration and dementia are also seen in clinical practice. 
In the present article we consider the abilities and disabilities of adults with cerebral palsy in activities of daily living, such as walking, self feeding and speech, and the decline of these skills with age. The source of information is the large California developmental disabilities data base $[36,38,40]$. The focus is therefore on the epidemiology of adults with cerebral palsy rather than on case studies. We also examine the pattern of survival for elderly persons with cerebral palsy.

\section{Materials and methods}

\subsection{Subjects}

The base population consisted of the 190,154 persons with developmental disability who received services from the State of California between January 1983 and December 1999. Services included medical treatment, occupational or physical therapy, and board and care. Eligibility for the California system is defined as "a disability which originates before an individual attains age 18 , continues, or can be expected to continue, indefinitely, and constitutes a substantial disability for that individual" [25]. All persons receiving services are evaluated approximately annually with a structured interview called the Client Development Evaluation Report (CDER) [10]. This instrument contains over 200 psychological, medical, functional, behavioral, and cognitive items. The reliability of the functional items has been assessed previously and judged satisfactory $[4,9$, 19,44,45]. The subjects of this study were all those in the data base said to have "cerebral palsy or other motor dysfunction," but excluding those with medical conditions that are degenerative or otherwise judged not to be cerebral palsy. A list of these exclusions is available from the authors.

Study period: Subjects were followed from January 1, 1983 to December 31, 1999.

Mortality information was obtained from annual computer tapes from the California Department of Health Services [32], and matched against the subjects on the basis of name, date of birth, and social security number when available.

Walking was classified into four groups: (1) does not walk; (2) walks with support or unsteadily alone at least 10 feet; (3) walks well alone at least 20 feet, balances well, but does not move up and down stairs without need for a handrail; and (4) walks well alone at least 20 feet, balances well, and moves up and down stairs without need for a handrail.
Feeding was classified into four groups: (1) tube fed (generally gastrostomy feeding); (2) not tube fed and does not feed self, must be fed completely by others; (3) not tube fed and finger feeds self with or without assistance; and (4) not tube fed and feeds self using utensils with or without spillage.

Other scales for activities of daily living, such as speech and personal hygiene, are specified in Table 1.

We distinguished four main types of residence: (1) dependent living in family home (often parents' home but sometimes the home of other family members); (2) own home, either semi-independent or independent; (3) community care facilities (usually small privately run group homes); and (4) facilities with higher level of medical care (including Intermediate Care Facilities and State Developmental Centers).

\subsection{Statistical methods}

The simplest way to investigate age-specific effects is to compare the proportions of persons who, for example, walk well at various ages. This is a cross-sectional analysis. Such analyses, however, reflect two very different trends: decline in function with increasing age, and a healthy survivor effect. The effect of the decline is to make elderly persons with cerebral palsy more disabled, on average, than the younger adults. The healthy survivor effect, however, means that the most disabled persons tend to die early, with the result that the elderly survivors tend to be the less disabled individuals. To separate these effects we employed both cross sectional and longitudinal analyses; the latter do not reflect any healthy survivor effect.

For the longitudinal analyses we constructed prognostic charts to track the changes in subjects' level of functioning over time. These charts give the probability that a subject in a given initial condition will be in any given condition after a specified number of years. Initially, $100 \%$ of the subjects are in the starting condition. Thereafter, the charts show the fraction who died, regressed, stayed in the same condition, or improved over the next 15 years. For example, Fig. 1a shows persons with $\mathrm{CP}$ who initially could walk well at least 20 feet, balance well, and climb stairs without need for a handrail at age 20. Different levels of walking ability are indicated by shading, and progress from bottom to top; the unshaded region corresponds to the highest level of ability, and the darkest shade being the lowest. Death (region E) is indicated in black. Area A (the white area) corresponds to persons in the cohort who are alive and retain the ability to walk well alone and 
Table 1

Functional status and other characteristics of persons with $\mathrm{CP}$ at ages 20, 40, and 60

\begin{tabular}{|c|c|c|c|}
\hline \multirow[t]{2}{*}{ Factor } & \multicolumn{3}{|c|}{ AGE } \\
\hline & $\begin{array}{c}20 \\
(N=8733)\end{array}$ & $\begin{array}{c}40 \\
(N=5169)\end{array}$ & $\begin{array}{c}60 \\
(N=904)\end{array}$ \\
\hline \multicolumn{4}{|l|}{ Gender } \\
\hline Male & $54 \%$ & $53 \%$ & $51 \%$ \\
\hline Female & $46 \%$ & $47 \%$ & $49 \%$ \\
\hline \multicolumn{4}{|l|}{ Walking } \\
\hline Does not walk & 35 & 35 & 40 \\
\hline Walks with support or unsteadily alone at least 10 feet & 25 & 29 & 35 \\
\hline Walks well alone at least 20 feet; requires handrail for stairs & 21 & 20 & 15 \\
\hline Walks well alone at least 20 feet, does not require handrail & 18 & 17 & 10 \\
\hline \multicolumn{4}{|l|}{ Feeding } \\
\hline Tube fed & 4 & 3 & 2 \\
\hline Not tube fed, does not feed self & 16 & 15 & 14 \\
\hline Finger feeds & 9 & 5 & 6 \\
\hline Uses utensils with or without spillage & 71 & 77 & 78 \\
\hline \multicolumn{4}{|l|}{ Personal Hygiene } \\
\hline Does not tend to personal hygiene & 40 & 37 & 32 \\
\hline Tends to some personal hygiene & 37 & 39 & 46 \\
\hline Tends to personal hygiene independently & 24 & 24 & 21 \\
\hline \multicolumn{4}{|l|}{ Bathing } \\
\hline Does not bath or shower self & 43 & 42 & 43 \\
\hline Performs some bathing and showering tasks & 25 & 27 & 32 \\
\hline Bathes or showers self independently & 31 & 32 & 25 \\
\hline \multicolumn{4}{|l|}{ Dressing } \\
\hline Does not dress by self & 25 & 20 & 18 \\
\hline Some dressing abilities & 50 & 50 & 58 \\
\hline Dresses self completely & 25 & 31 & 24 \\
\hline \multicolumn{4}{|l|}{ Ordering Food in Public } \\
\hline Does not order food in public & 51 & 45 & 40 \\
\hline Orders snacks or simple foods & 31 & 31 & 37 \\
\hline Orders complete meals independently & 18 & 23 & 23 \\
\hline \multicolumn{4}{|l|}{ Speaking } \\
\hline No use of words & 36 & 32 & 19 \\
\hline Simple or complex words, but limited vocabulary & 43 & 42 & 47 \\
\hline Broad vocabulary and uses it in appropriate context & 21 & 27 & 35 \\
\hline \multicolumn{4}{|l|}{ Residence Type } \\
\hline Own home dependently & 65 & 29 & 18 \\
\hline Independently or semi-independently in own home & 2 & 13 & 16 \\
\hline Community care facility & 20 & 19 & 22 \\
\hline Higher level care facility & 12 & 38 & 43 \\
\hline Other & 1 & 1 & 1 \\
\hline
\end{tabular}

climb stairs without need for a handrail. $100 \%$ of the persons start out at this level at age 20 , and $75 \%$ are still in this state 15 years later. Area B represents persons who walk well but can no longer climb stairs without the need for a handrail, $13 \%$ of the cohort having regressed to this level after 15 years. Area $\mathrm{C}$ represents persons who walk with support or unsteadily alone; $8 \%$ regressed to this level after 15 years. Area D represents persons who do not walk; $1 \%$ regressed to this level after 15 years (because of limitations in the resolution of the figure, the region corresponding to this group may not be discernable). Finally, the black area, area
E, represents persons who died, this being $4 \%$ after 15 years.

The probabilities for each cohort were computed using the Aalen-Johansen estimator [1], which was developed as an extension of the usual Kaplan-Meier estimator [23] to the case involving multiple live states [2]. As applied here, the Aalen-Johansen estimator is, in statistical parlance, consistent [13] regardless of any Markov assumption, and more efficient [13] than the extended Kaplan-Meier estimator proposed by Strauss and Shavelle [39]. The latter has been used to produce similar diagrams involving improvement 

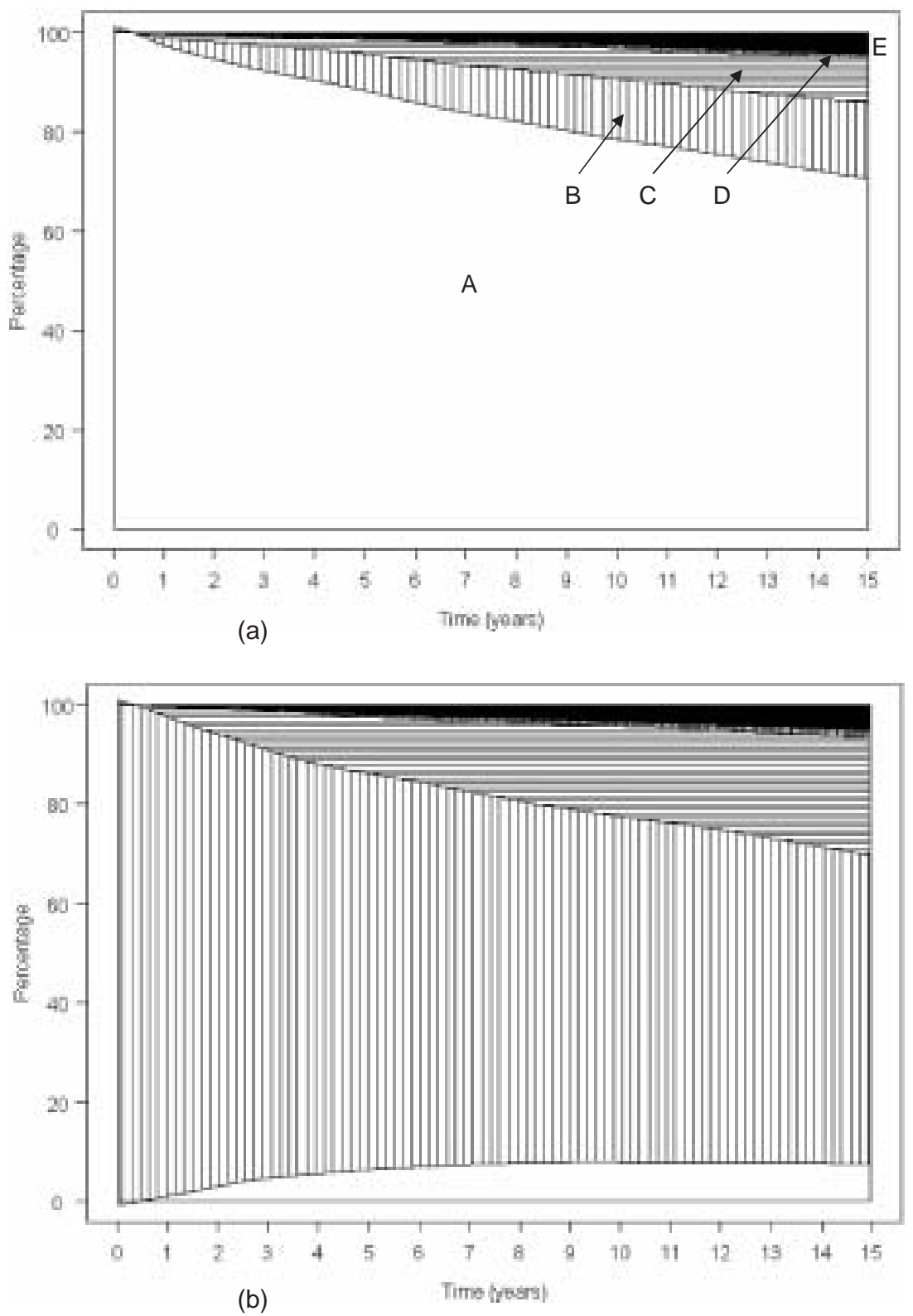

Fig. 1. Prognostic charts for persons of age 20. (a) Persons who initially walk well alone at least 20 feet, balance well, and climb stairs without need for a handrail. Initially (time $=0$ ) $100 \%$ of the subjects were in this category. For explanation see text. (b) Persons who initially walk well alone, balance well, and climb stairs with hand rail at best. This initial group had poorer ambulation than the initial group for Figure 1a. The graph shows that after 15 years: $8 \%$ had improved to the highest ambulatory level (namely, walks well alone at least 20 feet and balances well, and climbs stairs without hand rail); $62 \%$ after 15 years were at the same level as before; $26 \%$ had regressed; and $4 \%$ had died.

or decline in function of persons with developmental disabilities [36,38].

Survival curves were constructed for persons with $\mathrm{CP}$ for different functional levels at age 60. The Cox proportional hazards survival model [11] was used to determine the groupings for cohorts according to functional level. Briefly, this model estimates the effect of each factor on mortality risk, other factors held constant, on the assumption that relative risks stay constant over time. The adjustment for effects of other factors permits identification of factors having the most influence on survival. CDER functional items, which originally had between 4 and 9 levels, were collapsed when adjacent levels were not associated with significantly 
different mortality risks. The Kaplan-Meier productlimit survival method [11] was then applied to produce the actual survival curves for the cohorts of elderly persons.

All computations were carried out in SAS [31], with S-PLUS [33] used for graphics.

\section{Results}

There were 8733 persons with cerebral palsy of age 20 in the data base, 5169 of age 40, and 904 of age 60 . Table 1 shows the breakdown of subjects in each age group according to skills and disabilities.

At all ages, slightly more than half the subjects were male. Among the young adults (age 20), 39\% were able to walk well without support at least 20 feet, while $35 \%$ did not walk even with support. At age 60 only $25 \%$ were able to walk well alone and $40 \%$ did not walk at all. For ambulation, therefore, the decline with age outweighs the healthy survivor effect.

By contrast, with respect to speech the 60-year-olds tended to be higher functioning than the younger persons. For example, at age 20 the proportion of subjects who had no use of words was almost double the proportion who had a broad vocabulary and used it appropriately. At age 60, however, the proportions had reversed, the higher-functioning persons outnumbering the lower-functioning by $2: 1$. This suggests that (a) the decline in speech, if any, with advancing age is much less dramatic than the decline in ambulation, and (b) there is a strong healthy survivor effect: persons with such severe disabilities that they are unable to speak often do not survive to age 60 .

In general, the other skills described in Table 1 show an intermediate pattern, with a roughly similar profile of disabilities at all ages.

The item "ordering food in public" is included because it gives an indication of the individual's participation in normal social activity. At all ages, more than half of the subjects ordered at least some food in public.

More than half the young adults were living in their family's home, and most of the remainder were living in private group homes or facilities with a higher level of medical care. A larger proportion of the elderly subjects lived independent or semi-independently, and, not surprisingly, a large proportion (43\%) lived in facilities providing a higher level of medical care.

Figure 1 shows prognostic charts for persons initially of age 20 and followed for 15 years. Figure 1(a) follows subjects who initially had the highest level of ambulation: walks well alone at least 20 feet, balance well, and climb stairs without need for a handrail. 15 years later, about $4 \%$ had died (darkest shaded area, at the top of the figure), $8 \%$ could no longer walk without support and some $13 \%$ could still walk well alone at least 20 feet but could no longer move up and down stairs without use of a handrail. The remaining $75 \%$ retained their original level of ambulation. Figure 1(b) tracks the 20 year-old subjects who initially could walk well alone at least 20 feet but at best could climb stairs with the aid of a handrail. Fifteen years later, 26\% could no longer walk well alone for 20 feet.

Figure 2(a) follows 60-year-olds who initially walked well alone and climbed stairs without a handrail. Fifteen years later $70 \%$ were still alive, but the majority of the survivors were no longer able to walk well alone for 20 feet. Those who initially walked well for 20 feet but could not climb stairs without a handrail (Fig. 2(b)), were subject to still higher rates of mortality and decline in ambulation.

Table 2 summarizes the corresponding analyses for other activities of daily living. Although decline in function over a 15-year period is more common at age 60 than at age 20, the majority of elderly persons appear to retain their skills. For example, of the 60 yearolds who ordered food in public and were still alive 15 years later, $81 \%$ were still able to do so. Among those who initially fed themselves with utensils, $91 \%$ still did so 15 years later and only $6 \%$ had become fed by others. An exception is the ability to dress oneself, which appears frequently to decline after age 60 .

Figure 3 shows survival curves for persons initially of age 60 , stratified according to their mobility. The top (smooth) curve corresponds to the US general population (male and female combined). In the group who retained at least some independent ambulation, survival was not dramatically worse than the general population; for example, $75 \%$ were alive 10 years later, compared to $85 \%$ in the general population. Those who were nonambulatory at 60 but still retained some mobility (e.g., hand use or ability to roll over, or sit independently), fared somewhat worse, with $60 \%$ survival to age 70 . The small group with no functional mobility, however, had very poor survival.

\section{Discussion}

This appears to be the first study to examine the pattern of disabilities and mortality in a large population of adults with CP. Overall, the profile of skills and dis- 


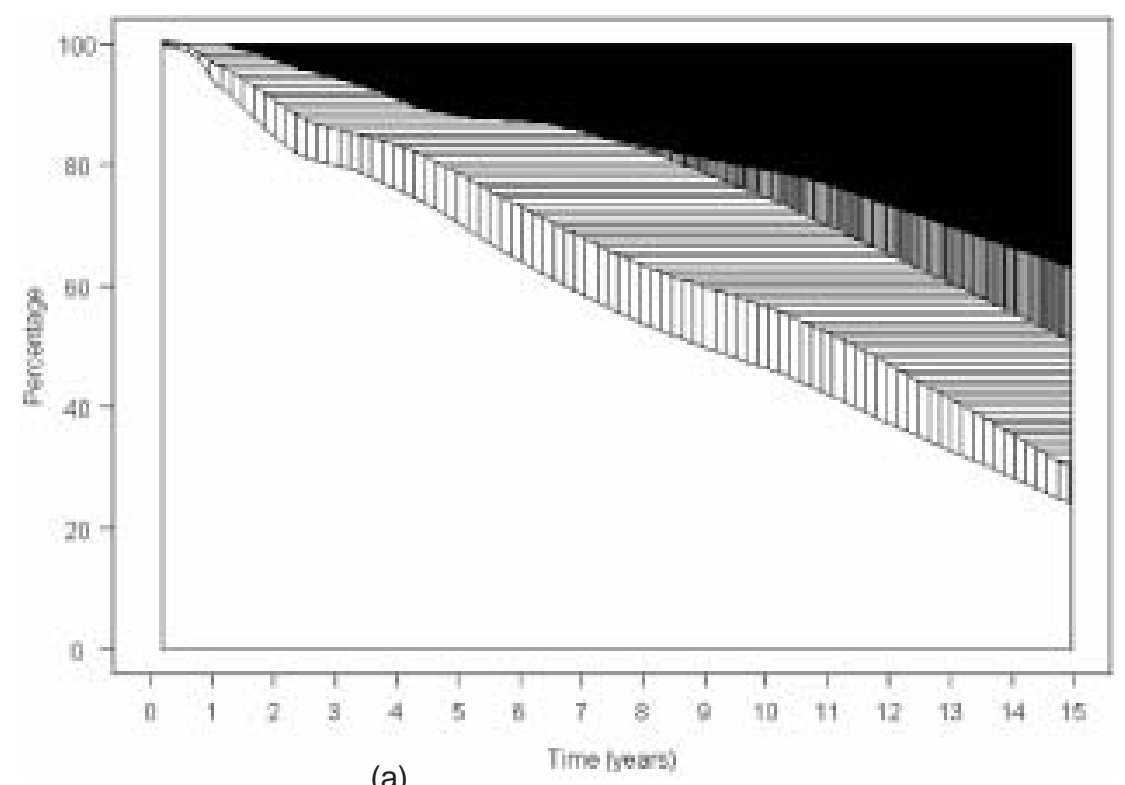

(a)

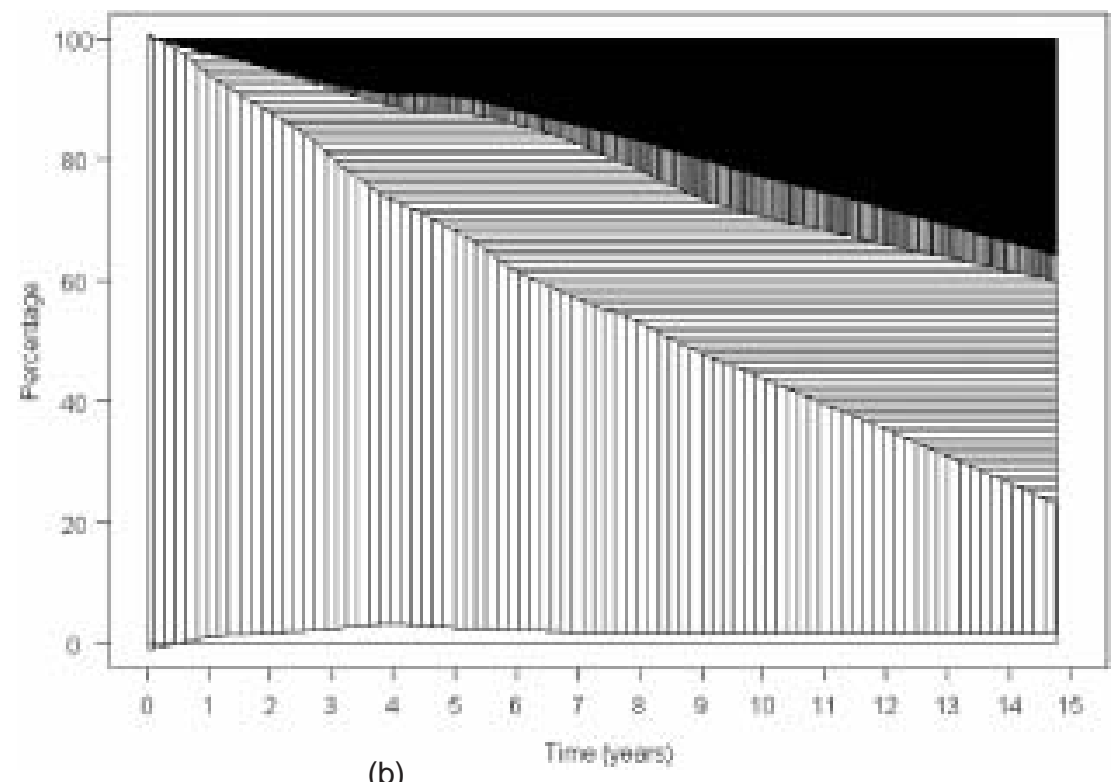

(b)

Fig. 2. Prognostic charts for persons of age 60. (a) Persons who initially walk well alone at least 20 feet, balance well, and climb stairs without need for a handrail. (b) Persons who initially walk well alone at least 20 feet, balance well, and climb stairs with hand rail at best.

abilities of persons at 60 was not markedly different from the pattern for younger adults. However, this reflects two trends that partially cancel out: a decline of functional abilities with age, but a healthy survivor effect - persons with the most severe disabilities rarely survive to age 60 . To separate the two trends we also followed the subjects longitudinally over a fifteen-year period. This revealed a dramatic decline in ambulation of elderly persons with cerebral palsy; even those able to walk well alone at age 60 were generally unable to do so 15 years later. There was also a marked decline in the ability of elderly persons with cerebral palsy to dress themselves. In several other respects, such as speech, self-feeding and ability to order food in public, however, the decline was much less severe. For example, of the 60 year-olds who fed themselves using utensils and who were still alive 15 years later, more than $90 \%$ had retained this ability. 
Table 2

Prognosis for function 15 years later of surviving persons with cerebral palsy

\begin{tabular}{llrr}
\hline Skill & State 15 years later & \multicolumn{2}{c}{ Percentage In Each State } \\
\cline { 2 - 4 } Starting State & & Start Age 20 & Start Age 60 \\
\hline Feeding & & 94 & 91 \\
Uses utensils & Same & 4 & 3 \\
& Only finger feeds & 2 & 6 \\
Dressing & Does not feed self & & 51 \\
Dresses self completely & & 80 & 46 \\
& Same & 19 & 4 \\
Ordering Food in Public & Some dressing & 1 & 81 \\
Orders complete meals & Does not dress self & & 17 \\
& Same & 89 & 3 \\
Speaking & Orders only snack or simple meals & 10 & \\
Has a broad vocabulary & Does not order food & 1 & 89 \\
& & & 9 \\
& Same & 89 & 1 \\
\hline
\end{tabular}

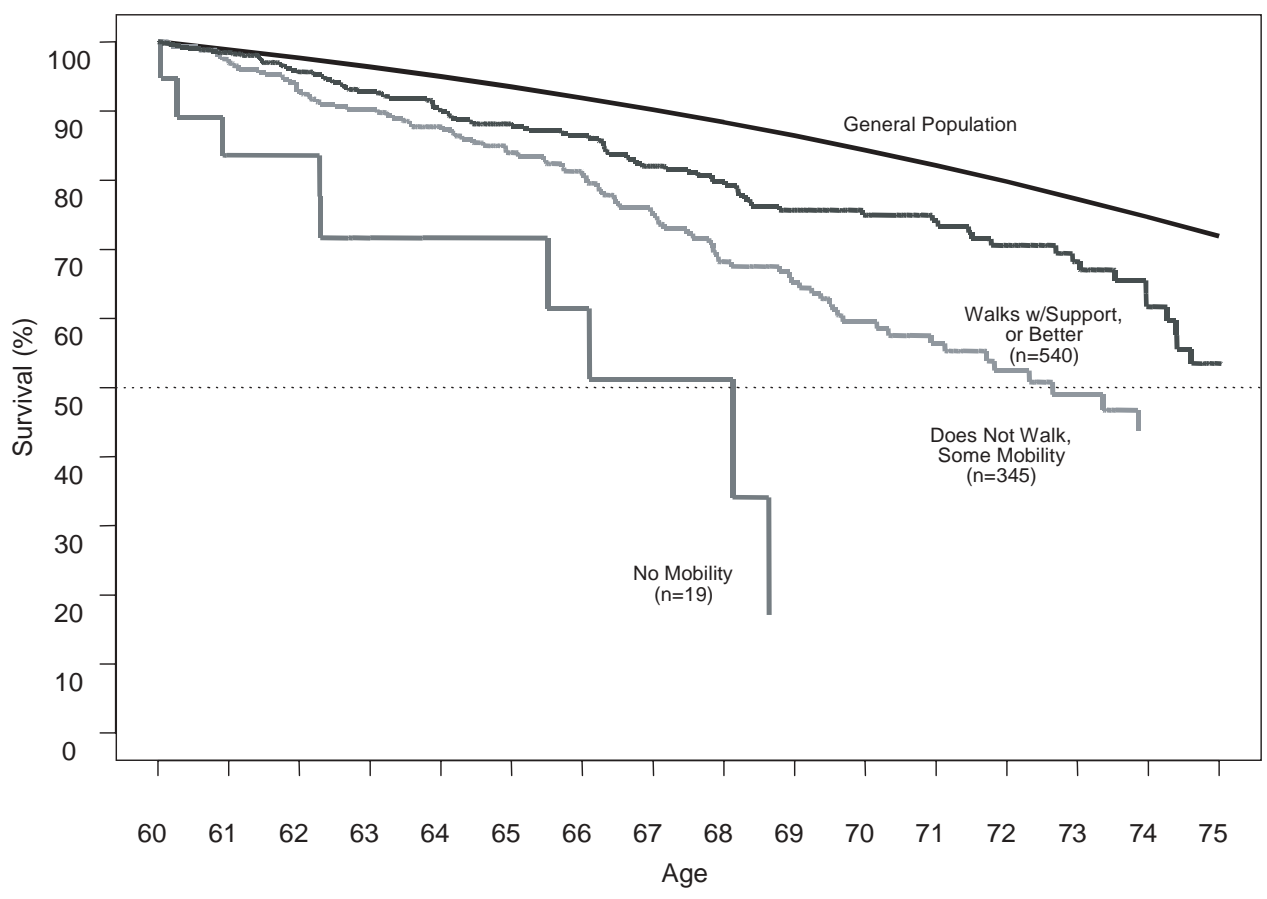

Fig. 3. Survival curves for persons with cerebral palsy at age 60, stratified by mobility, and for the general population.

Our finding that most persons with cerebral palsy eventually decline in gross motor function (notably, the ability to walk) is consistent with other reports $[8,28]$. Murphy et al. [28] found that roughly half the subjects who had become nonambulatory after the age of $10 \mathrm{had}$ become so by age 20 . The most common reasons given were the inconvenience of walking and increased joint pains.

A related issue is that musculoskeletal problems are common in adults with $\mathrm{CP}$, especially in those with spasticity but also in those with dyskinesia [6]. Many adults have required repeated orthopedic surgeries [28]. Murphy et al. [28] found that $90 \%$ of their nonambulatory group had lower extremity contractures, and scoliosis was present in over half of their subjects. Severe scoliosis was especially common in the nonambulatory group. Their study population consisted of persons in Northern California who contacted United 
Cerebral Palsy, and thus may have been weighted towards higher-functioning individuals.

A limitation of the present study is that it does not include all persons with cerebral palsy, but rather only persons receiving financial support or services from the State of California. It is generally believed that the great majority of persons with severe disabilities are included in the data base, but there is no doubt that many with milder impairments are not. As a result, the profile of functioning shown in Table 1 probably overestimates the prevalence of severe disabilities in persons with cerebral palsy as a whole. On the other hand, there is unlikely to be a serious bias in the subsequent tables and figures because these are stratified according to the severity of disabilities.

It may be noted that there are far fewer elderly subjects in the study than younger ones. For example, persons of age 20 outnumbered those of age 60 by almost 10 to 1 . This difference is larger than could reasonably be explained by mortality. It appears that many persons born in the decades before 1980 were not enrolled in the state system during their childhood and never became so, and thus are not in the data base. Again, the absence of such persons would affect the "mix" of different level of skills shown in Table 1; probably the excluded persons are on average higher functioning and thus less in need of services from the State. As noted, however, the other tables and figures are specific to persons of a given level of skill, and should be less subject to this bias.

The survival of adults with cerebral palsy who have some preserved mobility is relatively good. For elderly persons with CP who have retained at least some ability to walk, survival is not dramatically worse than in the general population. Survival is, however, much worse for those with very low functional ability. The key role of mobility as a predictor of survival in the elderly is consistent with extensive research on younger persons with CP $[7,12,16,20-22,38,40]$, traumatic brain injury $[5,34,35,41]$ and spinal cord injury $[14,15,17$, $42,46]$.

\section{Clinical considerations}

Loss of the ability to walk in adult life should perhaps be regarded as part of the natural history for some persons with CP. If that is indeed the case the therapeutic emphasis should perhaps be changed in childhood from maximizing motor skills to a more long-term view. As Bottos et al. [8] suggested:
... the traditional child- (or infant-) oriented approach concentrating mainly or exclusively on the achievement of independent walking, may not be an ideal approach to children with CP. Instead a more independence-oriented therapeutic approach would be appropriate.

It would follow that therapeutic approaches designed to promote muscle strengthening, the avoidance where possible of surgical procedures that produce muscle weakening, and the promotion of social and independence skills and educational achievements could be considered to be appropriate strategies. In this connection we note the recent use of group counseling to prepare persons with intellectual disability for the likelihood of age-related decline and loss [24].

The principles for promotion of the health and welfare of older people with $\mathrm{CP}$ are similar to those that apply in childhood. Firstly, consideration needs to be given to promotion and maintenance of mobility whenever possible. For adults it is important to avoid the development of muscle contractures and joint changes by the appropriate use of physiotherapy, hydrotherapy and medical and surgical treatments for spasticity. It nevertheless has to be recognized that mobility is likely to lessen with aging and a component of this is due to premature wear and tear changes of the joints.

Secondly, even when mobility is being lost, scrupulous attention to promoting and facilitating good seated posture by the use of appropriate wheelchairs and static seating is necessary and this needs to be combined with measures to treat and reduce pain, particularly that arising from stiffened joints. A component of appropriate postural support is avoiding or limiting the development of postural spinal scoliosis if possible.

The third principle of health care is the need to maintain good nutritional status, preferably by providing a suitable mixed diet orally. Should gastrostomy feeding be thought necessary, however, this should be commenced before there are clear signs of nutritional failure. The treatment of infections, epilepsy and constipation are also important, as is the maintenance of continence.

Health care must be provided within an appropriate social context. We do not believe it helpful to make generalizations on whether older people with CP should live in their own homes or in group living situations. What matters is that they receive appropriate health care and enjoy a satisfying range of occupational interests and social activities. The wish and will to live under these circumstances is particularly important. 


\section{References}

[1] O.O. Aalen and S. Johansen, An empirical transition matrix for nonhomogeneous Markov chains based on censored observations, Scandinavian Journal of Statistics 5 (1978), 141-150.

[2] P.K. Anderson, O. Borgan, R.D. Gill and N. Keiding, Statistical models based on counting processes, Springer-Verlag, New York, 1993.

[3] N. Ando and S. Ueda, Functional deterioration in adults with cerebral palsy, Clinical Rehabilitation 14 (2000), 300-306.

[4] M. Arias, E. Ito and N. Takagi, Concurrent validity of the Client Development Evaluation Report, in: Pacific state archives VIII, A.B. Silverstein and A.L. Fluharty, eds, University of California at Los Angeles, Developmental Disabilities Immersion Program, Pomona, CA, 1983, pp. 28-33.

[5] I. Baguley, S. Slewa-Younan, R. Lazarus and A. Green, Longterm mortality trends in patients with traumatic brain injury, Brain Injury 14 (2000), 505-512.

[6] M.C. Bax, D.P. Smyth and A.P. Thomas, Health care of physically hanidcapped young adults, British Medical Journal 296 (1988), 1153-1155.

[7] E. Blair, L. Watson, N. Badawi and F.J. Stanley, Life expectancy among people with cerebral palsy in Western Australia, Developmental Medicine \& Child Neurology 43 (2001), 508-515.

[8] M. Bottos, A. Feliciangeli and L. Sciuto et al., Functional status of adults with cerebral palsy and implications for treatment of children, Developmental Medicine and Child Neurology 43 (2001), 516-528.

[9] Citygate Associates, Independent evaluation of the Department of Developmental Services' community placement practices: final technical report, Citygate Associates, Sacramento, CA, 1998.

[10] Client Development Evaluation Report (CDER), California Department of Developmental Services, Sacramento, 1986.

[11] D. Collett, Modelling Survival Data in Medical Research, Chapman and Hall, London, 1994.

[12] J.U. Crichton, M. Mackinnon and C.P. White, The life expectancy of persons with cerebral palsy, Developmental Medicine and Child Neurology 37 (1995), 567-576.

[13] S.M. Day, Estimators of long-term transition probabilities of multistate stochastic processes, Doctoral Dissertation, University of California at Riverside, December 2001.

[14] M.J. DeVivo, J.S. Krause and D.P. Lammertse, Recent trends in mortality and causes of death among persons with spinal cord injury, Arhives of Physical Medicine and Rehabilitation 80 (1999), 1411-1419.

[15] M.J. DeVivo and S.L. Stover, Long-term survival and causes of death, in: Spinal cord injury: clinical outcomes from the model systems, S.L. Stover, J.A. DeLisa and G.G. Whiteneck, eds, Aspen publishers, Gaithersburg, MD, 1995, pp. 289-316.

[16] P.M. Evans, S.J.W. Evans and E. Alberman, Cerebral palsy: Why we must plan for survival, Archives of Diseases in Childhood 65 (1990), 1329-1333.

[17] H.L. Frankel et al., Long-term survival in spinal cord injury: A fifty year investigation, Spinal Cord 36 (1998), 266-274.

[18] C.G. Gajdosik and N. Cicirello, Secondary conditions of the musculoskeletal system in adolescents and adults with cerebral palsy, Physical and Occupation Therapy in Pediatrics 2149 68.

[19] C.W. Harris, R.K. Eyman and T. Mayeda, An interrater reliability study of the Client Development Evaluation Report: final report to the California Department of Developmental
Disabilities, Retardation Research Center, Lanterman State Hospital, Pomona, CA, 1982.

[20] J.L. Hutton, A.F. Colver and P.C. Mackie, Effect of severity of disability on survival in north east England cerebral palsy cohort, Archives of Disease in Childhood 83 (2000), 468-474.

[21] J.L. Hutton, T. Cooke and P.O.D. Pharoah, Life expectancy in children with cerebral palsy, British Medical Journal 309 (1994), 431-435.

[22] J.L. Hutton and P.O.D. Pharoah, Effects of cognitive, motor, and sensory disabilities on survival in cerebral palsy, Archives of Disease in Childhood 86 (2002), 84-89. Includes commentary by Dr. Lewis Rosenbloom.

[23] E.L. Kaplan and P. Meier, Nonparametric estimation from incomplete observations, JASA $\mathbf{5 8}$ (1958), 457-481.

[24] S. Kessel, J. Merrick, A. Kedem, L. Borovsky and E. Carmeli, Use of group counseling to support aging related losses in older adults with intellectual disabilities, Journal of Gerontological Social Work 38 (2002), 241-251.

[25] Lanterman Act, California Welfare and Institutions Code, Section 4512, 1969.

[26] R.A. Levine, A.E. Rosenbaum, J.M. Waltz and L.C. Scheinberg, Cervical spondylosis and dyskinesis, Neurology 20 (1970), 1194-1199.

[27] S. McCluer, Cervical spondylosis with myelopathy as a complication of cerebral palsy, Paraplegia 20 (1982), 308-312.

[28] K.P. Murphy, G.E. Molnar and K. Lankasky, Medical and functional status of adults with cerebral palsy, Developmental Medicine and Child Neurology 37 (1995), 1075-1084.

[29] M.E. Reese, M.E. Msall and S. Owen et al., Acquired cervical spine impairment in young adults with cerebral palsy, Developmental Medicine and Child Neurology 33 (1991), 153-158.

[30] P.L. Rosenbaum, S.D. Walter and S.E. Hanna et al., Prognosis for gross motor function in cerebral palsy, creation of motor development curves, Journal of the American Medical Association 288 (2002), 1357-1363.

[31] SAS Institute Inc., SAS version 6. SAS Institute Inc., Cary, NC, 1990.

[32] State of California, Annual Mortality Tapes, 1983-1997, Department of Health Services, Center for Health Statistics, Office of Health Information and Research, Sacramento, CA, 1983-1997.

[33] Statistical Sciences Inc., S-PLUS, version 3.1. Statistical Sciences, Inc., Seattle, 1990.

[34] R.M. Shavelle, D.J. Strauss, J. Whyte, S.M. Day and Y.L. $\mathrm{Yu}$, Long-term causes of death after traumatic brain injury, American Journal of Physical Medicine \& Rehabilitation 80 (2001), 510-516.

[35] R.M. Shavelle and D.J. Strauss, Comparative mortality of adults with traumatic brain injury in California, 1988-1997, Journal of Insurance Medicine 32 (2000), 163-166.

[36] D. Strauss, S. Ashwal, R. Shavelle and R.K. Eyman, Prognosis for survival and improvement in function in children with severe developmental disabilities, Journal of Pediatrics 131 (1997), 712-717.

[37] D.J. Strauss, S.M. Day, R.M. Shavelle and Y.W. Wu, Remote symptomatic epilepsy: Does seizure severity increase mortality? Neurology 60 (2003), 395-399.

[38] D. Strauss and R. Shavelle, Life expectancy of adults with cerebral palsy, Developmental Medicine \& Child Neurology 40 (1998), 369-375.

[39] D. Strauss and R. Shavelle, An extended Kaplan-Meier estimator and its applications, Statistics in Medicine 17 (1998), 971-982. 
[40] D.J. Strauss, R.M. Shavelle and T.W. Anderson, Life expectancy of children with cerebral palsy, Pediatric Neurology 18 (1998), 143-149.

[41] D.J. Strauss, R.M. Shavelle and T.W. Anderson, Long term survival of children and adolescents after traumatic brain injury, Archives of Physical Medicine and Rehabilitation 79 (1998), 1095-1100.

[42] D.J. Strauss, M.J. DeVivo and R.M. Shavelle, Long-term mortality risk after spinal cord injury, Journal of Insurance Medicine 32 (2000), 11-16.

[43] T. Treves and A.D. Korczyn, Progressive dystonia and paraparesis in cerebral palsy, European Neurology 25 (1986), 148153.
[44] K.F. Widaman, Interrater reliability of adaptive behavior assessments: item and factor levels, Presented at the 92nd annual meeting of the American Psychological Association; Toronto, Ontario, Canada, August 1984.

[45] K.F. Widaman, A.W. Stacy and S.A. Borthwick, Multitraitmulti-method of evaluating adaptive and maladaptive behavior of mentally retarded people, Presented at the 109th annual meeting of the American Association on Mental Deficiency; Philadelphia, Pennsylvania, May 29, 1985.

[46] J.D. Yeo, J. Walsh, S. Rutkowski, R. Soden, M. Craven and J. Middleton, Mortality following spinal cord injury, Spinal Cord 36 (1998), 329-336. 